\title{
IDÉIAS
}

\section{Perigo é Parlamento divorciado do real}

\author{
Armando Marques Guedes
}

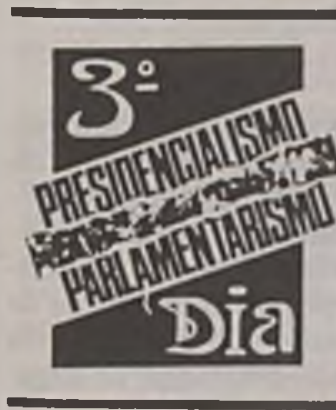

O título deste Seminário, e aliás está aqui em letras garrafais escritas, "Presidencialismo e Parlamentarismo", tem por objetivo discutir sobre as duas formas de governo. E todavia, o que tem vindo constantemente a debate é uma terceira forma de governo, o "semipresidencialismo". Chamo-lhe assim, para usar o nome técnico que lhe é atribuído. $E$, dissertando sobre ele, necessariamente, apreciaremos tanto presidencialismo quanto parlamentarismo.

Começo, liminarmente, por chamar vossa atenção pela designação semipresidencialismo. Muito pesa a um grande amigo meu, professor na Faculdade de Direito de Paris, o Prof. Maurice Diverger, que eu supunha haver sido quem impôs à circulação esta forma semipresidencialismo. É que se um dos componentes deste sistema misto fosse efetivamente o presidencialismo, nós teríamos reunidas nas mãos de uma mesma e única pessoa a dupla qualidade de Chefe de Estado e de Chefe de Governo, quando precisamente uma das características fundamentais do semipresidencialismo é a separação dessas duas funçōes atribuídas a duas personagens politicas distintas.

E isto resulta do fato da própria configuração do chamado semipresidencialismo, ser uma configuração tripla, isto é, que exige a formulação de três órgāos soberanos distintos: um é Chefe de Estado; um, Chefe de Governo e um órgão colegiado que é o Parlamento.

Não um sistema bipolar como é o presidencialismo. O presidencialismo assentase sobre a idéia de que como existem, o legislativo e o executivo frente a frente

Dr. Armando Marques Guedes é o Presidente do Tribunal Constitucional de Portugal, Conferencista do 3: Dia.

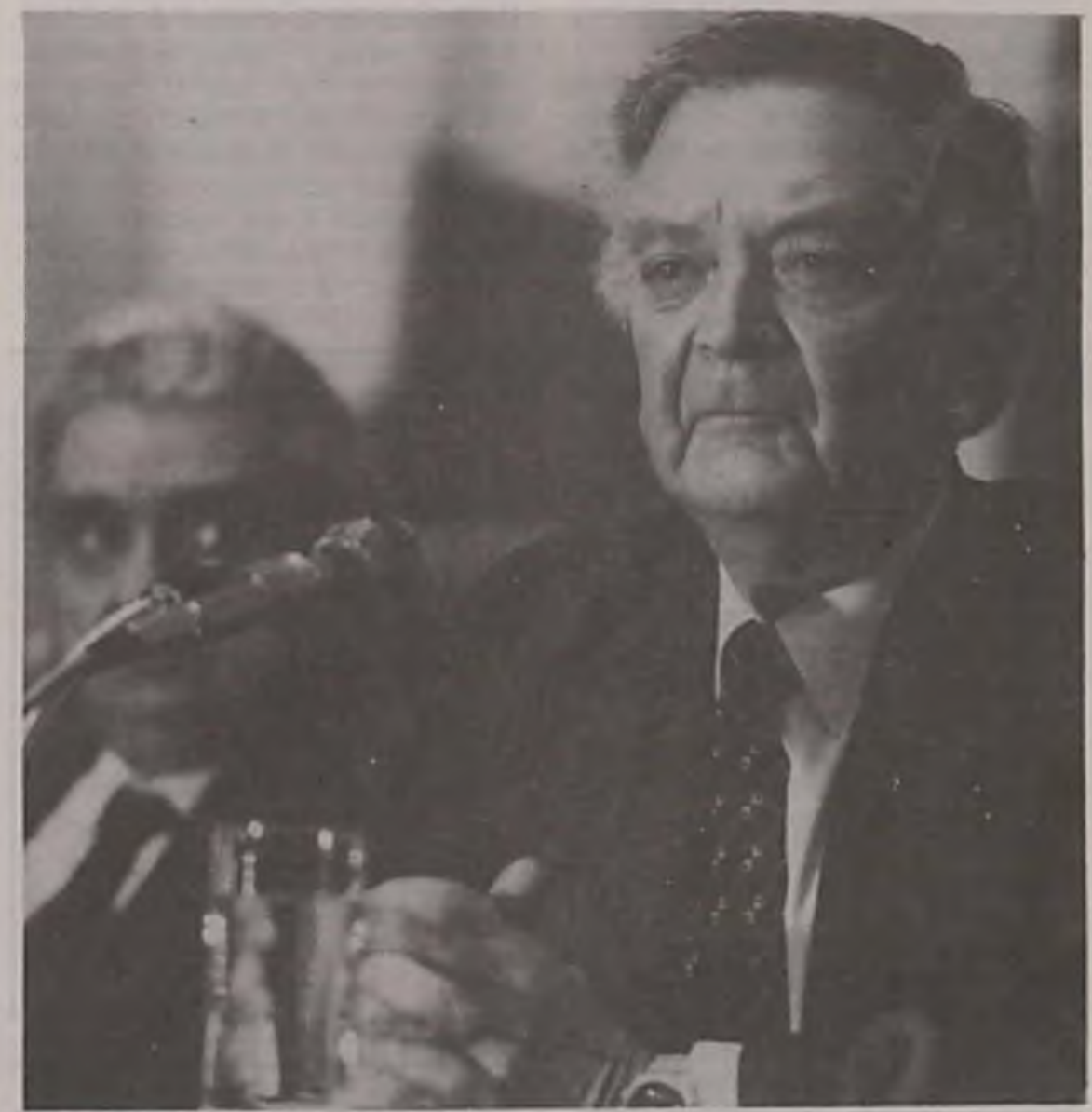

nem um nem outro tem reciprocamente poder sobre a ação política desenvolvida por outro parceiro.

\section{O SISTEMA ALEMĀO}

Isto tornaria impossivel pesar num sistema misto, um sistema bipolar como é o presidencialismo que é também tripolar, como o parlamentarismo, porque no parlamentarismo também é necessário que coexistam três órgãos, os mesmos que eu há pouco referi, um Chefe de Estado, um Chefe de Governo e um Parlamento. Justamente a confiabilidade dá-se ou torna-se possível, porque o tal outro sistema que ainda não me referi, que no chamado semi- presidencialismo é chamado a casar-se com o parlamentarismo: é ele também tripolar. É o sistema alemão dito de chanceler, é o sistema imaginável por um chanceler de ferro que foi Bismark, e que aparece, pela primeira vez, concretizado na Constituição Imperial Alemã de 1861, como Chefe do Estado, o Deutsche Kaiser, o Kaiser alemão, um Chefe do Governo, o Kanziler, o chanceler, que deu nome ao sistema e um órgão colegiado, bicameral, o Parlamento formado por Reichstag e por Bundersrat.

Qual é a diferença então, já que se apresenta aqui uma estrutura tripolar para o parlamentarismo que também é tripolar neste sistema, nesta forma de 


\section{IDÉIAS}

governo. A diferença está que, num e noutro caso, o executivo é chamado politicamente para responder. No parlamentarismo, o executivo tem de prestar contas ao Parlamento, no sistema de chanceler tem que prestar contas unicamente ao Chefe de Estado. Isto é, a manutenção em função do executivo, não depende da confiança do Parlamento no sistema de chanceler; depende exclusivamente da confiança do Chefe do Estado.

Era um sistema que foi acolhido pela Constituição portuguesa da segunda república, da Constituição de 1933, que vigorou afe 1974. A partir daí, de 25 de abril de 1974, apenas uma pequena parte, e esta mesmo a título somente provisório continuou em vigor.

Pois bem, nesta Constituição de 1933 havia um artigo, o artigo 112, que rezava assim: "A manutenção, no poder, do Presidente do Conselho, a designação do Chefe do Governo, depende somente da confiança do Presidente da República, e acrescentava-se, e não de quaisquer votaçōes da Assembléia Nacional, de votos de confiança, de não-confiança, de censura, ou do destino que nesta tiverem as suas propostas de lei. Porque sabido é, que uma das maneiras que o Parlamento tem de se manifestar, não digo apenas a sua não concordância, mas até o seu desagrado, à linha política que vem sendo seguida pelo executivo, é justamente não lhe aprovar as leis de que ele carece para governar, para realizar, em suma, o seu programa politico.

Um outro aspecto liminarmente, desejo por em evidência e para elc mé permito, do mesmo modo, chamar vossa atenção, quando este sistema intermicdiário se chama semipresidencialista, enculca-se qualquer coisa que na ordem dos fatos não é exata. Semi quer dizer metade, quer dizer $50 \%$, quer dizer que metade da ação de condução política pertence ao Chefe do Estado; continuamos a usar a designação semipresidencialista, sabendo que ela não é exata c que a outra metade, os outros $50 \%$, pertence ao Parlamento.

\section{O SEMIPRESIDENCIALISMO FRANCÊS}

Ora, nas constituições que há pouco mencionei e que compreendem leis fundamentais de países tão diversos como a Áustria, Islândia, Finlândia, Irlanda, França, Alemanha Federal, Es- panha, Portugal, o doseamento de poder político de fiscalização é muito diverso. Na França, por exemplo, é verdadeiramente, um semipresidencialismo. Já está na linha de fronteiras para um autêntico presidencialismo. Foi, por isso, até que o nome do Chefe do Governo francês, pela primeira vez mudou. Desde a Carta Constitucional de 1814, era sempre chamado Présidence de Conseil de Ministre. Porque passar a chamar-se Primeiro-Ministro? O Prof. Jean L. Parodi vai me permitir esta liberdade, é sabido o pouco afeto do pensamento político francês relativamente ao constitucionalismo britânico. É que, segundo a Constituição da 5 ?. República, quem preside os conselhos de ministros é o Presi-

\begin{tabular}{|c|}
\hline \\
O sistema parlamentar \\
misto destina-se a poder \\
funcionar alternadamente \\
como apoio do Executivo \\
para permitir a estabilidade \\
política do País. $O$ \\
Executivo ou tem como \\
esteio e como respaldo o \\
Parlamento, ou tem o \\
Presidente. O caso alemão \\
é significativo.
\end{tabular}

dente da República, não é mais o Chefe do Governo. Seria, em termos verbais e inexatos, continuar a chamar de político o Presidente do Conselho. $\mathrm{E}$ daí a escolha desta outra denominação, Primeiro-Ministro. E mais, o Presidente da República francês é reconhecidamente, tanto entremuros, em termos de política interna, como extramuros, em termos de política internacional, reconhecido como o interlocutor válido que em nome da França e do poder político, da soberania da França, falá. Mais ainda, segundo o artigo 16 da Constituição, que aqui já foi citado, o Presidente da República pode, em momentos difíceis da política nacional assumir, plenos poderes. É certo que a Constituição diz que, antes disso, deve ouvir os Presidentes das duas Câmaras - Câmara dos Deputados e do Senado - o Presidente do Conselho Constitucional e o Primeiro-Ministro.

No fundo, o Presidente da República vai ao ponto além do poder de um Presidente de um autêntico sistema presidencialista, embora mitigado, como é o Presidente norte-americano vai ao ponto de poder, temporariamente, afastar a aplicabilidade da Constituição. É isto que significa assumir plenos poderes.

Num desviamento não tão intenso, mas todavia em que por certo, mais da metade do poder está nas mãos do Presidente, é o sistema da Alemanha Federal. O meu colega Thaysen, há pouco citou o artigo 67 da Constituição de 1949, o Parlamento não pode, através de um voto de não-confiança, da negação da votação de um voto de confiança, solicitado pelo executivo, ou através da votação de um voto de censura, obter a queda do governo, se não dentro de 48 horas. Reparem na exigüidade do prazo arbitrado: se não for em 48 horas designado, por maioria o novo chanceler, pode solicitada ao Presidente Federal a dissolução do Reichstag e o Bundersrat.

O Presidente Federal não é obrigado, todavia, a exceder ao pedido de solução que lhe é endereçado pelo chanceler. Pode, por circunstâncias da politica, puramente ocasionais, da Alemanha Federal, manter em funções aquele parlamento e manter em funçōes aquele chanceler. E diz o artigo 81: "se assim o decidir, entra-se num estado de necessidade política em que o Presidente pode promulgar a legislação de que o chanceler precisa para poder governar, mesmo contra o voto do Parlamento". Querem V. Exas. mais clara demonstração do extensissimo poder, que sem dizer que o sistema é semipresidencialista, a Constituição alemã de 1949 , confere ao Presidente Federal? No pólo oposto, a Áustria, desde sempre a figura eminente na política austríaca, tem sido o chanceler, o Chefe do Governo, porque tem tido atrás de si, a maioria parlamentar. Ele pode governar, certo de que o Parlamento não o derrubará, e isso é tiro pela linha de frente, pela ribalta, na cena política austríaca; isto vai tendo o peso político na figura do Presidente da República.

Há, por consegüinte, e poderia conduzir a minha análise relativamente aos instantes em que acontecem nos países 
europeus que adotaram este sistema semipresidencialista, um doseamento variável, consoante às circunstâncias do caso e não é apenas em razão da letra das respectivas leis fundamentais, mas também em razão de elasticidade dos próprios dispositivos constitucionais que deliberadamente o consentem, há um diferente e variável baseamento, entre os poderes que, frente a frente são dados ao Presidente e ao Parlamento. É errado, também; chamar-lhe semiparlamentarismo ou semipresidencialismo. Com alguma razão na década de 70 , quando a França ingressou numa vivíssima discussão, sobretudo nos meios universitários, relativamente à qualificação do sistema de governo, acolhido pela Constituição da 5. República, um colega meu, professor na Faculdade de Direito na Universidade de Clermont Ferrand, num artigo que teve larga retumbância na imprensa, dizia: "chama-se, ou há quem chame ao sistema francês mi-présidentiel, ou então, se quiser, miparlementaire. $\mathrm{Na}$ realidade a palavra "mi" está aqui mal, porque lê-se niparlementaire e ni-présidentiel.

O sistema misto é um sistema que se destina, estou a falar no puro plano teórico, sem ter na exceção agora, de casos concretos relativamente ao país a, b, c, ou d. O sistema destina-se alternadamente para poder funcionar como apoio do executivo permitindo a estabilidade politica do pais. $\mathrm{O}$ executivo ou tem como esteio, como respaldo, o parlamento, ou tem como respaldo, como apoio, o Presidente. $O$ caso alemão é significativo quanto a este ponto. Citei o caso alemão e deveria citar o caso espanhol, porque embora com uma configuração que não é exatamente igual, a chamada missão construtiva de censura que a Constituição de 1978 admite, vem na prática a ser um dispositivo destinado à mesma finalidade: poder dar apoio ao Chefe de Estado, poder dar apoio, no fundo, ao Chefe do Governo. Limitar dentro de certo espaço a faculdade que poderia decisivamente concorrer para a desestabilização do pode de derruba, que está implicado no poder de fiscalização política, confiado ao Parlamento, na componente ou segunda componente parlamentar do sistema.

Por que é que vocês portugueses adotaram na Constituição de 1976 o sistema semipresidencialista?

Não foi por pura moda. Nós portu gueses, pais periférico na Europa, an- siando sempre por contatos com a cultura européia, temos, tradicionalmente uma atitude não digo referencial, mas particularmente receptiva às soluções que nos são dadas pelos outros países europeus, mas não foi isso que aqui imperou. O que aqui imperou foi a experiência vivida da história constitucional portuguesa. Tivemos, sucessivamente em Portugal, periodos de parlamentarismo, de presidencialismo e de governo de chanceler. $\mathrm{E}$ isto levou-nos a concluir que nenhum dos três era aquele que veramente se adaptava à idiossincrasia do povo português e às exigências da sua política, tanto social e acima de tudo social, como econômica.

\section{O PERIODO DO}

\section{PARLAMENTARISMO}

\section{Hoje a evolução das idéias faz-se muito mais rapidamente que há 50 anos, mercê dos "mass- midia": se a opiniāo pública era volátil, hoje o é ainda mais e confiantemente. $O$ risco está no mandato excessivamente longo do Parlamento diante dessa mutação social.}

Por longuíssimos 60 anos, mais de 60 anos da terceira Carta Constitucional portuguesa, 1842 até a Proclamação da República em 1910, Carta Constitucional que me orgulho aqui de dizer neste momento, que é em muitos dos seus artigos, a pura transcrição da Constituição Imperial Brasileira de 1824. O autor de ambas foi o mesmo, pelo menos o inspirador. Benjamin Constant.

Pela Carta Constitucional, ou meIhor, à sombra da Carta Constitucional, neste longo $3^{\circ}$. periodo de vigência que se estendeu até 1910 , ao que se assiste e à alternância no poder de dois grandes partidos, o partido regenerador $e$ o partido progressista. Lembrando aquilo que se passava já então na Grã-Bre- tanha, aquilo que os ingleses chamam de Swing At The Pendulum, a alternância no poder dos dois partidos, um e outro se revezam. Em Portugal a substituição era, na realidade, acordada por consenso entre o rei de uma banda e o chefe dos dois partidos políticos, que iam ambos de concerto, pedir ao monarca que em face do desgate sofrido por aquele desses dois partidos, que já a tempo demais se encontravam no poder, este pedisse ao rei que aceitasse a sua demissão e designasse 0 chefe do outro partido para ser o Presidente do Conselho, isto é, para constituir um novo governo.

Foi o que permitiu que numa obra publicada já no dia alvar deste nosso século que agora está perto do fim, aquele que foi o Presidente do Conselho em dado período e o era quando o rei de Portugal, o penúltimo foi assassinado em 1908, João Franco, numa obra em que compila a correspondência que trocou com o monarca. O título desta obra é "Cartas de el rei" e diz, em certo passo, isto: "a Inglaterra e os governos resultam das eleições, em Portugal as eleições saem dos governos". Porque efetivamente enquanto na Inglaterra se devolvia e ainda hoje se devolve a opinião pública, mais corretamente ao eleitorado, ditar o veredicto de quem deve ser o Primeiro-Ministro."

Em Portugal isso era combinado pelos próprios partidos políticos, como há pouco descrevi, com o monarca. $O$ sistema era um sistema falseado e não melhorou a situação. O sistema, e ele igualmente parlamentar, que foi adotado nos seus 16 anos de vida pela primeira república portuguesa, 1910 a 1926, curiosamente, a Assembléia Nacional Constituinte em 1910, 1911, propendia para o modelo norte-americano. Quem sabe uma vez mais por inspiração dos nosso irmãos brasileiros que desde 1889 , tinham instaurado a República e adotado um sistema presidencialista, mas acabou por vencer na Assembléia Nacional Constituinte a idéia de ir em frente, da solução francesa de então. A preponderância da cultura francesa, na cultura portuguesa, é uma constante desde a função de Portugal, em meados do século XXII. E foi esta que acabou por obter ganho de causa. $\mathrm{Na}$ tentativa de importar a solução norte-americana, ficou tão só na Constituição de 1911 a designação dada ao parlamentar bicameral, composto por uma Câmara dos Deputados e por um 


\section{IDÉIAS}

Senado de Congresso da República. Mas nada mais do que isso, porque foi a cópia fiel das instituições da terceira república francesa. As leis constitucionais de 1865 , que na história constitucional francesa se convencionou chamar constituição da terceira repúblíca não são na realidade um texto constitucional. São três leis constitucionais desgarradas, completadas por uma quarta lei, em que se previa um sistema parlamentar, isto é, o sistema tripolar que eu há pouco referia: a correlação entre o legislativo e o executivo sob a égide de um árbitro, que seria o Presidente da República. O Presidente da República, para resguardar o qual perante a eventualidade do regresso das idéias monárquicas e sobretudo da pressão bonapartista que é o equivalente monárquico do presidencialismo puro, um Presidente que deveria ser eleito em sessão conjunta com as duas Câmaras do Parlamento francês. O Presidente da República é eleito à exceção simultânea da Câmara dos Deputados e do Senado e ele tem o poder de designar o Presidente do Ministério, como então se chamou, e por proposta deste os restantes membros do governo. Mas não tem a faculdade de dissolver o Parlamento. Por quê? porque era essa a prática política francesa. As leis constitucionais da 3. República previam este poder de dissolução como forma desse árbitro, que era o Presidente da República, ter um poder de contenção quer do Exécutivo, quer do Legislativo, quando porventura uma diferença ou até um aberto conflito se instalasse entre ambos.

O primeiro presidente francês da 3 . República foi Michel Adolph Pierre, num breve trecho conseguiu reunir contra si a animosidade das duas Câmaras do Parlamento. Foi substituído pelo marechal Max Wollon, que em 1877 ousou invocar a sua faculdade de dissolução do Parlamento. O escândalo foi tal que até 1940, termos da vivência das leis constitucionais da 3a República, mas nenhum Presidente francês da República se atreveu a invocar esse pode de dissolução. É como se ele tivesse sido riscado do texto constitucional. Foi esse sistema parlamentar, de assembléia, isto é, já na linha de fronteira para o puro sistema de assembléia, como o havia imaginado Jean Jacques Rousseau, em que praticamente é contra a posição do Legislativo e Executivo não existe porque o Executivo é apenas uma dependência do Legislativo, não tem vida autônoma própria, foi este sistema que veio a agravar o desafeto dos portugueses com o parlamentarismo. Junto com o pendor natural do português para a multiplicação dos partidos políticos. Quando a Constituição de 1911 deixou de vigorar, existiam em Portugal 24 partidos políticos. Era impossível governar, sentir através de coligações, e mesmo estabelecida uma coligação, digo-lhes isso porque vivi a tragédia de meu pai, ministro das finanças do último governo da primeira República, mesmo quando se conseguia uma coligação, ela tinha que ser feita de tanto estudar, que o tempo se consumia a manter a coligação e nada sobrava para governar. Todavia o que muito quem

Em Portugal tivemos
sucessivamente épocas de
parlamentarismo, de
presidencialismo e de
governo de chanceler. $E$
isto nos levou a concluir
que nenhum dos três era
aquele que veramente se
adaptava à idiossincrasia
do povo e às suas
exigências sociais e
econômicas.

a pensasse, atribuía aos homens e não às leis, neste caso a Constituição, o insucesso do parlamentarismo. E para a triste politica ensaiar um sistema intermédio, como os da Constituição de 1933, do fim da República, do sistema imperial alemão, da Constituição de 1871. O governo, mantendo-se no poder exclusivamente, mas teve a confiança do Presidente da República, só que o sistema acolhido pelo artigo $112 \mathrm{da}$ Constituição, permitia, na realidade, três formas distintas de governo. Permitia, em primeiro lugar aquela que foi praticada até o final. A figura política de proa foi sempre o Presidente do Conselho.

O Dr. Salazar I, o Dr. Marcelo Caetano, até 25 de abril de 1974. Mas po- diam também, como o próprio Prof. Marcelo Caetano descreveu nas suas lições de ciência política e direito constitucional que funcionava com um centro de gravidade localizado na pessoa do Chefe de Estado, do Presidente da República. Isso não Implicaria a alteração de uma vírgula do artigo 112 . Mas tive a ocasião de dizer isso numa conferência que perante o instituto dos altos estudos militares, cujo corpo docente ainda hoje pertenço, além do ensino que faço na Faculdade de Direito de Lisboa e na Universidade Católica de Lisboa, esse artigo 112 consentia ainda um terceiro modo de governo. Como eu dizia, a manutenção em funções do governo dependia tão só da confiança do Presidente da República, não das votações da Assembléia Nacional ou do destino negativo que nesta tivessem as suas propostas de lei. E, se o Presidente da República resolvesse fazer como Luiz XVIII fez na França, sobre a Carta Constitucional de 1814, que era dar ouvidos ao Parlamento, à Assembléia Nacional. E, por conseguinte, manter ou retirar a sua confiança ao Presidente do Conselho, de acordo com o sentido da própria Assembléia Nacional.

Teríamos, também aí, sem mudar uma vírgula, a transição para um sistema parlamentar. De qualquer modo isso exigiria um interpretação dos juristas e razão tinha o marquês de Pombal, na lei do erário público, que é de 1762 , onde em certo artigo, a propósito da adjudicação dos dois monópolios do estado então existentes, que era o monopólio do tabaco e monopólio do sabão, e dizia, e parece que o artigo que foi do punho dele, dizia: "nos contratos da adjudicação dos tempos do tabaco e dos tempos do sabão, é proibido incluir cláusulas suscetíveis de inteligência científica, ou de interpretação de doutores".

A fraseologia da Constituição é mesmo mais exigente no que diz respeito à possibilidade de o Presidente exonerar o governo do que quanto à possibilidade que igualmente existe de demitir a Assembléia. Quanto ao governo diz, que só pode fazer, quando o ruar continuamente, reproduz a mesma frase, das instituições democráticas. No outro artigo diz que o Presidente da República pode dissolver a Assembléia Nacional observados o disposto no artigo tal. O que esse artigo diz é que a Assembléia da República goza de um estado de graça, durante os primeiros 
seis meses depois de eleita, durante esses seis meses o Presidente da República não a pode dissolver, e que também - Presidente da República, não pode, nos seis meses finais do seu mandato, dissolver a Assembléia da República.

É que hoje a evolução das idéias fazse muito mais rapidamente a mercê da ação dos "mass-mídia" do que se fazia há cinqüenta anos atrás. Se a opinião pública era há cinqüenta anos atrás volátil, hoje o é - ainda mais e confiantemente. $\mathrm{O}$ risco está em que o Parlamento com um mandato relativamente longo a partir desta altura não seja a imagem na repartição, na recíproca relação das forças políticas nela representadas, relativamente ao que pessoas que, num meio social, a repartição também deve ter forças políticos. Um Parlamento divorciado da realidade politica do pais, um Parlamento em que detém a maioria um ou dois partidos que já não são majoritários entre os dois partidos.

Nós tivemos, na primeira constituição escrita portuguesa que esteve para ser, se não fora antes concluida, a independência brasileira, também a primeira Constituição escrita no Brasil, a Constituição de 1822, ano da independência da França e isso que é o Brasil, um mandato da Assembléia Nacional, da Assembléia Legislativa, de apenas dois anos. Ainda hoje, naquela Constituiçāo cujo bi-centenário, nós neste ano celebramos, que a Constituição norte-americana, a legislatura é apenas de 2 anos. Cada dois anos muda por inteiro a Câmara dos representantes e é refrescado num inteiro mandato, como o sistema é bipolar e o Presidente não pode dissolver o Congresso norte-americano, o resultado é matematicamente ao meio do mandato do Presidente haver, na sua frente, um Congresso de cor política que pode ser, como agora neste momento sucede, contrária à cor política do Presidente.

Ora, e com isto transito para o último dos pontos nesta minha exposição, quero crer como resultados praticados da aplicação nestes dez anos transcorridos desde a entrada em vigor da Constituição de 1976, no meu país, com os resultados que foram alcançados, dizemos o seguinte: 11 anos se entremedeam entre 1976, 25 de abril, quando a Constituição principiou a vigorar, e 1987, nestes onze anos tivemos quatro Parlamentos, sabido como o mandato dos Parlamentos portugueses é de 4 anos, parece que o Parlamento também, porque três deles foram dissolvidos antes do término do seu mandato. O único que chegou a termo foi a primeira Assembléia da República que principiou a funcionar em 1977.

Eu não estou com isto a advogar a necessidade de se ter um mandato muito curto, porque esse não dá tempo. A realização do móvel legislativo, por parte do parlamento. Por muito que em toda parte se vá procurando descobrir soluções para manter, com a devida respeitabilidade, o órgão legislativo, não tanto como órgão político, mas como órgão legislativo, não tanto como órgão político, mas como órgão titular daquela que é função que dá um nome, que é função legislativa. Na Inglaterra, por

\begin{tabular}{|} 
Uma das maneiras que o \\
Parlamento tem de se \\
manifestar à linha politica \\
que vem sendo seguida pelo \\
Executivo, é justamente não \\
lhe aprovar as leis de que ele \\
carece para governar, para \\
realizar, em suma, o seu \\
programa político.
\end{tabular}

exemplo, logo a seguir à Primeira Guerra Mundial, contra mais de 820 Honors in Council, isto é, de decretos leis, e o Parlamento pode produzir, escassamente, duas dúzias de leis, e o fosso alargouse enormemente. Posteriormente, o que nós fizemos na Constituição de 1976 e principalmente na sua revisão, que teve lugar em 1982, foi reservar certas matérias para a capacidade, a consciência legislativa do Parlamento como reserva o Parlamento, nem sequer pode delegar através da autorização no executivo e outras. Reservá-las para o Parlamento sim, mas deixando-se na mão dele, que o entender, poder autorizar o governo sobre sua fiscalização, dependendo da sua ratificação, pode o governo ser ele o criador da lei nesse âmbi- to, nesses domínios, nessas matérias.

Não quero alongar o meu tempo. Não teria também muito mais como um professor universitário, como acima de tudo aqui pretendo ser, expondo serenemente a realidade das coisas e aquilo que o texto constitucional português diz, não quero alongar-me naquilo que eu diria ser discriminar com algum interesse, mas que certamente não seria já objetivo e por isso mesmo não seria científico, até porque os 11 anos de experiência honestamente, não permitem ir muito mais além. Eu direi totalmente que se apressarmos e persistirmos ainda hoje em manter o que no dominio da doutrina se pode defender pacifica esta opinião, a de que o sistema apropriado é o sistema errôneamente chamado de semipresidencialista, que colhe dos três sistemas tri-polares. O sistema de chanceler e o sistema parlamentar, o que eles têm de bom como compensação reciproca que lhes permite confinar como esteio e suporte do governo. De modo a permitir uma ação governamental continuada e quando digo governamental é porque não quero dizer governativa, é porque quero dizer da ação de governar o país que essa tanto cabe ao executivo como a maneira aristotélica. Aristóteles vivia um governo justo, não um governo de leis, não um governo de homens. É um governo furtado aos caprichos, à boa ou má vontade aos sentidos indicativos que ele, o astro da convicção humana, como diria Malraux, porque a lei, e mesmo Aristóteles já sustentava é a razão e desprovida da paixão, eu não posso se não dizer o que ele disse e acrecentar que o retorque que fizemos na Constituição em 1982 não é por certo o último, mas que o sistema tem que permitir uma estabilidade que não se verificou nem sobre a vigência do sistema de chanceler, porque aí era uma estabilidade imposta pela força, não democraticamente nem durante o sistema Parlamentar da primeira República, ou da parte final da monarquia liberal, nem durante o curtíssimo espaço de um ano, que tanto foi aquele em que Portugal experimentou o sistema presidencialista, sob o Presidente Sidônio Paes, tragicamente assassinado um ano depois de ter iniciado as suas funções, funçōes que não foram recebidas. Mostra bem que se tratava de uma forma de governo que não ponderava a maneira de pensar e de sentir do eleitorado português." 